\title{
O RESGATE DA SUBJETIVIDADE: DIFERENTES OLHARES
}

\author{
H. C. CÂMARA ${ }^{1 *}$, F. A. S. OlIVEIRA ${ }^{1}$, A. A. C. CÂMARA² e E. C. CÂMARA ${ }^{3}$ \\ ${ }^{1}$ Universidade do Estado do Rio Grande do Norte - UERN \\ ${ }^{2}$ Governo do Estado do Rio Grande do Norte e da Prefeitura Municipal de Caicó \\ ${ }^{3}$ Secretaria de Educação do Estado de Mato Grosso \\ redlehcc@gmail.com*
}

Artigo submetido em novembro/2015 e aceito em abril/20xx

DOI: 10.15628/holos.2016.3649

\section{RESUMO}

Este trabalho objetiva fazer uma reflexão acerca da relação entre sujeito e sociedade, que ao longo da história, tem desencadeado inúmeras discussões em virtude de uma visão dicotômica que ressalta que esses dois existem separadamente, quando na verdade só existem porque estão imbrincados nas relações sociais que ambos desencadeiam. Nesse sentido, propõe-se fazer uma aproximação acerca da compreensão de sociedade a partir de Emile Durkheim (1993), bem como apresentar apontamentos teóricos que tentam superar a ênfase ora dada a sociedade, ora ao sujeito. Seguindo essa reflexão e para alcançarmos nosso objetivo, recorremos aos olhares de Pierre Bourdieu (2010), Michel Foucault (1995) e Maurice Merleau-Ponty (2006), que, sob suas óticas, são fundamentais para entendermos a formação do homem e sua relação com a sociedade. Em linhas gerais, conclui-se que a crítica na ênfase em um olhar que valoriza a formação do sujeito a partir da sociedade ou no que dá ao ser individual as rédeas exclusivas de sua formação. Bourdieu (2010), Foucault (1995) e Merleau-Ponty (2006), não delegam o processo de formação do ser exclusivamente as estruturas nem somente as questões eminentemente subjetivas. Cada um deles, considerando seus recortes teóricos, identificam que a formação do sujeito não pode ser fundada somente em um aspecto, mas se faz a partir da relação entre o ser individual e o ser coletivo. Esperase, com este trabalho, contribuir para a construção de um novo olhar acerca do sujeito e da sociedade desencadeado a partir das noções teóricas aqui elencadas.

PALAVRAS-CHAVE: Sociedade, Sujeito, Relações sociais.

\section{THE RESCUE OF SUBJECTIVITY: DIFFERENT LOOKS}

\begin{abstract}
This work aims to do a reflection on the relationship between subject and society that throughout history, has triggered numerous discussions due to a dichotomy that highlights that these two are separate, when in fact only exist because they are interconnected in social relations that both create. In this sense, it is proposed to make an approach about the understanding of society from Emile Durkheim (1993), and present theoretical approaches that attempt to overcome the emphasis one moment it is given the society, in the next to the individual. Following this reflection and to achieve our goal, we resort the eyes of Pierre Bourdieu (2010), Michel Foucault (1995) and Maurice Merleau-Ponty (2006) that under their optical, are fundamental to understand the formation of man and
\end{abstract}

his relationship with society. In general lines, concludes that the critical the emphasis on a look that values the formation of the subject from society or in giving the individual exclusive reins of their training. Bourdieu (2010), Foucault (1995) e Merleau-Ponty (2006) do not delegate the individual formation process only the structures, not only eminently subjective questions. Each considering its theoretical clippings identifies that the formation of the subject cannot be founded only on one aspect, but it is from the relationship between the individual self and the collective being. It is hoped this study was to contribute to the construction of a new look about the subject and society triggered from the theoretical notions listed here.

KEYWORDS: Society; Subject; social relations. 


\section{SITUANDO O LEITOR}

A sociedade ao longo da história foi alvo de inúmeras reflexões. Para ciência, compreendêla era algo necessário, pois, o seu entendimento possibilitaria uma atuação mais eficaz sobre ela e, consequentemente, uma forma de melhor operar em frente aos problemas que lá emergem. Vale destacar que os entendimentos acerca da sociedade foram diversos e nem sempre convergiam para os mesmos olhares. Na verdade, muitas eram tão diferentes que a inserção de um pensar anularia o outro, aliás, anular o outro consistiu em uma das formas de validar o próprio olhar.

A ciência tornar-se-ia, assim, palco de luta para conquista pela hegemonia de algumas formas de pensar sobre outras. Subsidia ainda a construção de diferentes teorias para a explicação do funcionamento da sociedade. No entanto, é preciso ressaltar que quando uma teoria consegue tornar-se hegemônica, ela faz muito mais do que apenas explicar uma dada realidade. Na verdade ela a constrói. Tomás Tadeu da Silva (2007) aponta que nenhuma teoria se limitaria a descrever e explicá-la, isto porque estaria irremediavelmente implicada no seu processo de produção, de tal maneira que ao descrever um objeto, inventa-o. A teoria seria tão somente uma visão particular da realidade.

Nenhuma teoria teria valor absoluto. Nem mesmo as palavras poderiam ser dadas como verdade. Friederich Nietzsche (2007), referindo-se à palavra, destaca que ela seria tão somente metáforas das coisas, pois de sua essência nada sabemos, a não ser uma explicação dada por outrem e que se constitui como verdade. Para o autor, esta seria:

Um exército móvel de metáforas, metonímias, antromorfismos, numa palavra só, uma soma de relações humanas que foram realçadas poética e retoricamente, transportadas e adornadas, e que, após uma longa utilização, parecem a um povo consolidadas, canônicas e obrigatórias: as verdades são ilusões das quais se esqueceram que elas assim o são [...] (NIETZSCHE, 2007, p. 36).

As discussões que ora apresentamos nestas poucas linhas nos permitem pensar sobre o que seria verdade, pois, constituídas como metáforas, não dão conta de reproduzir a realidade em plenitude. É sempre uma apropriação de uma parte a fim de tentar dar conta da totalidade. Nesse sentido, o conhecimento materializa-se como uma verdade que não pode ser carregada de certezas.

Edgar Morin (2007), ao discutir a incerteza do conhecimento, aponta que a construção e apreensão do conhecimento está constantemente sujeita ao erro e a ilusão, isto porque o conhecimento sempre parte das percepções, as quais são ao mesmo tempo traduções e reconstruções cerebrais com base em estímulos ou sinais captados e codificados pelos sentidos, portanto comporta interpretação e é carregada de subjetividade, de visões de mundo e de princípios. $\mathrm{O}$ autor também infere que o conhecimento científico seria um poderoso meio de detecção de erros e ilusões, mesmo assim, ele próprio pode apresentar erros e ilusões, não estando imune e não podendo ser cristalizado como o conhecimento certo (MORIN, 2007).

Além desse aspecto, não se pode pensar a constituição da verdade na ciência fora de um campo de lutas, de poder, em busca da conquista ou manutenção da hegemonia. Nesse prisma, a verdade é ponto de vista concebido como certo. Não é neutra e, consciente ou inconsciente, é 
carregada de valores e formas de pensar dos indivíduos que a formulam e a defendem. $O$ conhecimento, pintado de verdadeiro e de neutro, disseminar-se pela sociedade, chegando a todos os lugares, abrangendo cada vez mais os indivíduos.

É assim que o conhecimento da ciência atua. Impõe-se através de paradigmas, de forma tão intensa e quase "determinista". As verdades que transmite destitui as que a ela não converge. Por isso mesmo, no "seio das verdades", há as que se sobressaem. As que se constituem como hegemônicas, falseando os outros conhecimentos e argumentando em prol de suas assertivas.

É nessa conjuntura, na qual o "poder" das verdades manifesta-se intensamente, que a sociedade foi pensada. Nessa diversidade de formas de concebê-la, algumas inferências ponderaram sobre a relação entre a estrutura social e indivíduos. Alguns trabalhos versaram ora com ênfase nos sociologismos, em que a sociedade constituía-se enquanto constructo dos sujeitos que nela estavam inseridos, de modo a considerar que os homens seriam produtos das relações estabelecidas no seio social. Ora nos psicologismos, nos quais a ênfase na formação social seria os indivíduos.

O que se mostra nestes estudos, em virtude da excessiva evidência dada a sociedade ou ao indivíduo, é constituição de um pensamento dual, como se os indivíduos existissem separados da sociedade ou se só existissem como tal em virtude do espaço social em que se relaciona, seja ele macro ou micro. Essa visão dicotômica constitui-se em um problema social e filosófico. Torna-se então necessário superar essa dicotomia e refletir como os indivíduos se constituem como sujeito, ao mesmo tempo em que estão inseridos em uma trama de relações sociais. É essa reflexão que guiará esse estudo.

Inicialmente, faremos uma aproximação a compreensão de sociedade a partir de Emile Durkheim e, em seguida, apresentaremos algumas discussões que tentam superar a ênfase ora dada a sociedade, ora ao sujeito. Para tanto, recorremos aos olhares de Pierre Bourdieu, Michel Foucault e Maurice Merleau-Ponty, que, sob suas óticas, representam a formação do homem e sua relação com a sociedade.

É necessário deixar claro que estes não são os únicos autores que questionam o poder determinístico da sociedade, contudo, a escolha foi feita porque as discussões dos desses teóricos tem adquirido respaldo no meio acadêmico, bem como porque, por mais que haja críticas as suas teorias, acreditamos que apresentam elementos essenciais para a reflexão sobre a sociedade, principalmente se considerarmos a inserção do homem enquanto sujeito do processo de constituição de sua própria vida.

\section{A OBJETIVIDADE DA SOCIEDADE: O OLHAR DE EMILE DURKHEIM}

A obra de Durkheim, de maneira geral, pretende pensar a organização social e os elementos dela constitutivos e, para tanto, estabelece uma analogia com um organismo vivo. Nas palavras de Paulo Meksenas (1998) a sociedade na obra do autor, apresenta-se como um imenso corpo social, que funcionaria harmonicamente na interelação entre os seus diversos órgãos, os quais realizariam as funções a eles inerentes.

As instituições como a família, a igreja, o estado, a escola, dentre outros, seriam os órgãos desse corpo social, cada qual possuindo objetivos próprios que se diferenciariam, mas mutuamente inter-relacionados, a fim de garantir a harmonia na sociedade (MEKSENAS, 1998). 
Os indivíduos inseridos na sociedade, portanto, participando da organização social materializada nas instituições, estariam objetivamente submetidos a ela. Rogério J. de Almeida (2011) ratifica isto ao pontuar que os indivíduos desde o nascimento já estariam sujeitos a uma série de predeterminações antecipadamente estabelecidas e impostas pela sociedade, como as crenças, os costumes, as normas e as regras de ser e de agir, que se internalizando, iriam constituir as consciências individuais.

É a partir das vivências dos indivíduos no mundo social, que a lógica da sociedade vai neles se constituindo. Segundo Durkheim (1993, p. 168)

[...] A sociedade só faz sentir sua influência se ela é um ato, e ela só é um ato se os indivíduos que a compõe estão reunidos e agem em comum. É pela ação comum que ela toma consciência de si e se afirma; ela é, antes de tudo, uma cooperação ativa. Mesmo as idéias e os sentimentos coletivos só são possíveis graças aos movimentos exteriores que os simbolizam [...].

A consciência adquirida é, dessa forma, uma consciência adquirida externamente, visto que se forma a partir do empréstimo dos elementos essenciais que a compõe. Para o Durkheim (1993), até a consciência do caráter humano só pode ser pensada sob forma humana, portanto, a partir de uma compreensão formada coletivamente.

O pensamento dependeria, então, de aspectos externos ao sujeito e não de uma ação individual e por si. Durkheim (1993) apresenta uma relação intrínseca entre o pensar e a vida coletiva. Em suas palavras, é na

[...] vida coletiva que o indivíduo aprendeu a idealizar. Foi assimilando os ideais elaborados pela sociedade que se tornou capaz de conceber o ideal. Introduzindo na sua esfera de ação, a sociedade fê-lo contrair a necessidade de se alçar acima do mundo experimental e forneceu-lhes ao mesmo tempo os meios de conceber um outro mundo. Pois esse mundo novo ela o construiu ao se construir a si mesma, visto que ela o exprime. Assim, tanto entre os indivíduos como no grupo, a faculdade de idealizar nada tem de misteriosa (DURKHEIM, 1993, p. 171).

Além do mais, cabe ratificar que o pensamento construído, pauta-se em uma ordem estabelecida pelo corpo social. Para Meksenas (1998) é a existência de uma moral social, também chamada de consciência coletiva, que determina a conduta das pessoas na sociedade.

A consciência coletiva, nessa perspectiva, teria a função de "manter a ordem, pois, sem essas leis de convivência, a vida em sociedade seria impossível" (MEKSENAS, 1998, p. 34).

Vale ainda considerar, que a aquisição dessa consciência, mesmo se dando em cada ser individual, só é possível porque é feita a partir de conceitos que são construídos socialmente. Os conceitos segundo Durkheim (1993, p. 175)

[...] são, antes de tudo, representações coletivas, acrescentam àquilo que nossa experiência pessoal pode nos ensinar tudo que a coletividade acumulou de sabedoria e de ciência ao longo dos séculos. Pensar por conceitos não é simplesmente ver o real pelo lado mais geral: é projetar sobre a sensação uma luz que ilumina, a penetra e a transforma. 
As discussões que ora apresentamos conduzem a percepção de uma relação que se estabelece entre o indivíduo e a sociedade de forma predominantemente determinística da última em relação a primeira. A formação do sujeito individual estaria condicionada aos aspectos sociais que definiria não só as regras de inserção social, mas, e principalmente, a consciência deste sujeito, a qual estaria irremediavelmente ligada a uma consciência coletiva. O "eu" individual não seria nada mais de que um reflexo do "nós". As ações do indivíduo, embora pareçam ser definidas por ele, na verdade são produtos de forças externas que se inseriram na consciência dos indivíduos de tal maneira que se confunde com a própria individualidade. Uma individualidade que pouco teria de individual.

\section{BOURDIEU E A FORMAÇÃO DO SUJEITO}

A organização social, mais especificamente a relação entre a estrutura e os agentes sociais constituem-se como elemento central nos estudos de Bourdieu. $\mathrm{O}$ autor parte de uma crítica ao determinismo das estruturas, as quais desconsiderariam o sentido que os agentes dariam a suas ações, como se estas fosse iminentemente determinadas pela organização estrutural da sociedade.

Segundo Nádia G. Gonçalves e Sandro A. Gonçalves (2010, p. 20), Bourdieu procura superar a dicotomia existente entre estrutura e agente, ou mais especificamente, "entre a abordagem objetivista, determinista, na qual os indivíduos são totalmente submetidos às estruturas, e a subjetivista, em que os indivíduos são privilegiados na análise e têm reconhecida e valorizada sua liberdade em relação às estruturas".

Nessa perspectiva, não haveria o entendimento de que na formação do homem existe uma separação entre a objetividade e a subjetividade, estabelecendo maior valor a um ou a outro aspecto. Na verdade, o processo formativo é relacional, portanto não pode desconsiderar nem a objetividade do mundo, nem a subjetividade dos agentes.

Para Peter Berger e Thomas Luckmann (1985) os sujeitos são constituídos a partir de processos relacionais, dessa forma, a partir do contado com o outro. Assim, é na vivência social que os indivíduos se formam, contudo em uma perspectiva diferente da apresentada por Durkheim, isto porque os autores não desconsideram na formação da consciência, a subjetividade.

Os autores pontuam que a formação dos indivíduos se dá à medida que a realidade é apreendida, ou seja, vai se tornando coerente (BERGER \& LUCKMANN, 1985). Assim a formação do sujeito estaria atrelada as compreensões e representações, isto porque, o que sou, como penso, como me comporto só é possível a partir das compreensões que tenho da vida. É compreendendo que posso inserir-me na sociedade e nela viver. Constitui-se, assim, uma via de mão dupla, na qual a medida que vou compreendendo a realidade vou me construindo e sendo quem eu sou (BERGER \& LUCKMANN, 1985).

Sobre esse aspecto Sartre (apud BAUMAN, 1998, p. 39) afirma que "Só no próprio momento em que acredito que possuo, eis que, por uma inversão curiosa, ele me possui..."

Cabe considerar que esta realidade é percebida pelos membros ordinários da sociedade a partir do senso comum, os quais vão dando sentido a ela à medida que o mundo se torna coerente para eles (BERGER e LUCKMANN, 1985) 
Essa compreensão coaduna com a visão de Bourdieu (2010) quando faz uma analogia sobre o aprender um certo jogo, de modo que, quando mais se conhece as suas regras, mais este jogo parece natural para os agentes. Essa naturalização se dá a partir da interiorização, que seria o processo de incorporação das disposições culturais. $O$ processo de interiorização atua profundamente nos indivíduos, de tal maneira que quanto mais eu conheço a realidade e encontro sentido nele, mais a incorporo. Bourdieu (2010, p. 142) evidencia que, quando "Os agentes bem ajustados ao jogo são possuídos por ele e tanto mais, sem dúvida, quanto melhor compreendem".

Há, de certa forma, um processo relacional e dialético em que estariam envolvidas a subjetividade e a objetividade. Haveria, assim, a interiorização da exterioridade e exteriorização da interioridade.

Nesse sentido, a interiorização e incorporação dos diferentes capitais poderia se constituir em habitus, o qual seria produto da interiorização dos princípios de uma cultura, que permanece interiorizadas nos agentes, mesmo após finalizados os estímulos. O habitus, assim, nunca estaria apartado do sujeito.

Para Bourdieu (2010), o habitus seria produto de um processo de interiorização/exteriorização das práticas. O habitus poderia ser considerado um "princípio ativo, irredutível as percepções passivas, de unificação das práticas e as representações (isto é, equivalente, historicamente constituído, logo, historicamente situado, desse eu existência devemos postular (...) "(BOURDIEU, 2010, p. 77).

Complementando esse entendimento, Denice Catani (2012, p. 19) afirma que o habitus seria constituído por um conjunto de disposições para a ação e consistiria numa "história incorporada, inscrita no cérebro e também no corpo, nos gestos, nos modos de falar, ou em tudo que somos".

Essas linhas parecem conduzir-nos a uma compreensão em que a sociedade seria também estruturalista. Contudo, é a partir do conceito de habitus que o autor se diferencia dessa concepção determinista da sociedade. Segundo Catani (2012, p. 19)

[...] será o conceito de habitus que Bourdieu explicará as ações dos indivíduos, mas não como sendo determinadas pelo mundo exterior ou em decorrência de movimentos de interioridades independentes (livres). Para ele, trata-se de reconhecer "a interioridade da exterioridade", ou seja, os modos de incorporação do funcionamento da realidade social num processo de interiorização que obedece às especificidades de lugar e da posição de classe dos agentes. Trata-se de explicar como a interioridade se faz presente no exterior, o que quer dizer: interessa principalmente as relações entre a incorporação dos padrões sociais de respostas ao mundo e a produção de novas respostas sob forma de ações ou práticas sociais.

O que se deve ter ciência é que na vivência social há a apreensão de diversos capitais, sejam eles cultural, social, simbólico ou econômico, que se entrecruzam. Esses diferentes capitais estariam imersos em maior ou menor grau em diferentes campos, sendo por isso, mais ou menos valorizados no lugar onde se inserem.

A incorporação dos capitais culturais, por exemplo, mesmo se constituindo em um arbitrário cultural, não seria em momento algum uma ação absolutista, em se tratando de 
apreender formas de ser e de agir, por isso não há a produção de um habitus social em série, mas sim de um habitus individual, que seria o princípio gerador das respostas que damos à realidade social. Outro aspecto a considerar é que o maior acesso aos diferentes campos e capitais constituise também na ampliação das possibilidades de apropriação da realidade. Enfim, as respostas dadas pelos sujeitos, embora partam de padrões sociais incorporados, forjam-se considerando sempre a subjetividade do agente que, enquanto sujeito, tem possibilidade de fazer suas escolhas. Quanto mais acesso aos capitais, mais poderá ser sujeito de si.

\section{O SUJEITO EM MICHEL FOUCAULT}

As discussões de Michel Foucault transitam na relação entre o saber, o poder e a constituição do sujeito, contudo, dado o objetivo deste texto, o enfoque aqui proposto incidirá tão somente na reinserção do sujeito no processo de constituição do indivíduo, embora tenhamos ciência de que as questões do saber e do poder estão presentes de forma inextrincável nesse processo constitutivo.

Cabe inferir inicialmente, que não se pode negar ação de objetivação da sociedade sobre os indivíduos, todavia essa objetivação para Foucault (1995) nunca é absoluta. Embora os indivíduos pareçam ser "automaticamente determinados", eles constantemente escapam das objetivações.

Mesmo Foucault, posicionando-se desta maneira, algumas críticas a ele são feitas, delegando-o um caráter estruturalista. Dentre estas críticas estão a de Giddens, a qual é apresentada nas reflexões de Gomes, Almeida e Vaz (2009). Segundo os autores, Giddens afirmaria que o sujeito em Foucault se constituiria na relação entre poder e saber, contudo essa formação seria objetivada e o sujeito construído seria o heterônomo, destarte, incapaz de agir por si.

Gomes, Almeida e Vaz (2009) refutam o entendimento de Giddens, enfatizando que na fase tardia de Foucault essa crítica não teria tanta sustentação, isto porque a ideia de poder como governo fundar-se-ia em uma postura ativa do indivíduo. O poder como governo constituir-se-ia em uma "teoria da ação" que conseguiria "fugir da fundamentação circular do poder e da resistência em direção a práticas subjetivadoras que visem a liberdade" (GOMES, ALMEIDA \& VAZ, 2009, p. 308).

Não haveria, desse modo, como conceber em Foucault, que as relações de poder constituiriam um sistema de dominação que controlaria tudo e, dessa maneira, não havendo espaço para ação individual (GOMES, ALMEIDA \& VAZ, 2009). Ao contrário, na ideia de poder como governo a ação individual comporta a resistência.

A inserção da resistência frente às objetivações sociais é apresentada por Foucault (1995) no texto "o sujeito e o poder". Neste, o autor destaca que o poder só poderia ser exercido na relação e, na relação, não haveria como desconsiderar a presença dos sujeitos. Nesse prisma, o exercício do poder poderia se definido como

[...] um conjunto de ações sobre ações possíveis; ele opera sobre o campo de possibilidade onde inscreve um comportamento dos sujeitos ativos; ele incita, induz, desvia, facilita ou torna mais difícil, amplia ou limita, torna mais ou menos provável; no limite, ele coage ou impede absolutamente, mas é sempre uma 
maneira de agir sobre um ou vários sujeitos ativos, e o quanto eles agem ou são suscetíveis a agir. Uma ação sobre ações (FOUCAULT, 1995, p. 243).

Se partirmos da perspectiva de que o exercício do poder é um exercício de ações sobre ações, mas considerando que estas acontecem em sujeitos ativos, não seria possível afirmar que haveria uma ação absoluta sobre os sujeitos submetidos a ação, nem muito menos em que medida a aceitação da coerção se processaria. Ora, se os mecanismos de coerção fossem absolutos, nenhuma mudança poderia ocorrer, pois a naturalidade das coisas, enquanto vontade e efeito de verdade, tomaria o ser de tal forma que não conseguiria subverter a ordem. A paz total e a normalidade das coisas seriam infinitas.

A liberdade para Foucault (1995) surge como aspecto determinante para pensar o sujeito enquanto ser da ação, visto que não há exercício do poder sem liberdade e esta, para os sujeitos, materializa-se na possibilidade de ação e reação que não são determinadas, mas ganham forma a partir das próprias escolhas.

Nessa perspectiva, poder-se afirmar que o exercício do poder só teria existência na relação, portanto, nas práticas. Sendo relacional, as práticas se constituiriam no lugar onde a resistência e a fuga poderiam emergir.

Para Gomes, Almeida e Vaz (2009), a vontade individual, encontra-se assim no cerne da questão de Foucault, dando ao sujeito a capacidade de recusar e resistir e, desta forma, a possibilidade de elaborar sua própria subjetividade, afastada estaria afastada da "vontade de verdade" e do poder normalizadores externos ao sujeito.

Uma forma reflexiva de ser sujeito pode ser visualizada, segundo Gomes, Almeida e Vaz (2009) no final da vida de Foucault, através do que chama de práticas de si, na qual o autodomínio e o autoconhecimento se constituiriam como elementos determinantes na formação da identidade.

Essas práticas se aproximariam do conceito de identidades para si ou identidades reflexivas, apresentado por Claude Dubar (2006), a qual poderia ser definida como uma forma identitária pautada em uma reflexão interior, dessa forma, considerando o investigar, o argumentar, o discutir, em uma reflexão sempre a partir de si e não do outro.

Das práticas pontuadas por Foucault, emerge o conceito de cuidado de si, que para o autor, seria o despertar para si, a partir da ocupação e preocupação consigo mesmo, o que inclui a própria reflexão sobre o pensar, na maneira de ser, nas atitudes, portanto, nas reflexões e práticas que constituem a história constitutiva das práticas de subjetividade (FOUCAULT apud ROSO, 2012).

Assim como as identidades reflexivas, não seria equívoco dizer que o cuidar de si não se distanciaria em nada da perspectiva de sujeito apresentada por Giddens (apud GOMES, ALMEIDA e VAZ, 2009) situando-o em um projeto reflexivo de auto identidade. O que poderia conduzir a formação de um sujeito que se constitui a si mesmo, como senhor de suas práticas, dessa maneira, em um exercício de si e sobre si. Dessa maneira, permite a realização de uma série de operações sobre si, em seu corpo, em seus pensamentos, em suas condutas, de maneira a possibilitar o alcance de certo modos de ser, os quais seriam produto de certo critérios de escolha livre e razoável do próprio sujeito. 
O cuidar de si só pode se constituir a partir de si mesmo, assim sendo, de um eu para si e nunca do eu para o outro. As percepções externas a mim não se instituiriam como um cuidar de si. Além do mais, até mesmo o cuidar do outro só seria possível, de fato, quando eu consigo me perceber. É a partir da percepção de mim mesmo que tenho condições de perceber o outro.

Para finalizar, a inserção do sujeito no processo de formação do homem, inserido na dinâmica relacional, sujeito e sociedade, ganha mais respaldo quando Foucault (apud GOMES, ALMEIDA \& VAZ, 2009, p. 314) discute a arte da existência ou estética da existência, que consistiria em "estratégias de subjetivação do poder moderno, na medida em que caberia ao indivíduo efetuar operações sobre si e para se transformar na e constituir uma forma desejada de existência".

Nesse sentido, mesmo no espaço mais autoritário que possa existir, a resistência está presente, assim sendo, não poderíamos desconsiderar a existência de um sujeito que se relaciona com o mundo e se constitui ao mesmo tempo. Aplica-se nos casos em que o trabalho segue uma linha de desenvolvimento de assuntos contínuos, conforme a estrutura dada abaixo:

\section{MERLEAU-PONTY: O SER ENQUANTO TOTALIDADE}

Merleau-Ponty, ao refletir sobre o processo de formação humana, trás uma reflexão que se aproxima as de Foucault e Bourdieu, no sentido de que considerar esse processo formativo não como dual, mas relacional. Todavia, o olhar deste autor parte de outro prisma. A crítica de Merleau-Ponty incide com maior ênfase na excessiva valorização das questões subjetivas, desconsiderando outros aspectos, como o social.

O teórico fundamenta-se em um olhar fenomenológico e pensa o homem não como fruto tão somente de uma estrutura selvagem, nem muito menos poderia ser reduzido a uma consciência, sendo assim, produto da relação entre estes dois aspectos, não constituído, mais instituído (CHAIUÍ, 2012).

Nessa perspectiva, a ênfase no naturalismo ou no objetivismo, segundo Merleau-Ponty (apud CHAUÍ, 2012), materializa-se como problemas centrais da filosofia e, segundo Husserl (apud CHAUÍ, 2012), superar essa questão se torna imperativo, de maneira que seja possível e tome o mesmo lugar, tanto as coisas do ser, quanto as das normas.

A infraestrutura precisa portanto ser admitida pela fenomenologia, isto porque é naquela, onde nascem nossas teses, que não podem ser produzidas simplesmente pelos atos da consciência (MERLEAU-PONTY apud CHAUÍ, 2012). Poder-se dizer que a infraestrutura é o fundo a partir do qual toda e qualquer experiência se produz.

Vale uma ressalva: A noção de ser em Merleau-Ponty é sempre pensada a partir da totalidade, portanto não é um aglomerado de partes que comporiam o todo. Corpo e alma não seriam coisas desconexas, mas uma unidade. Nesse contexto, o uso de termo corpo pelo autor não pode ser compreendido em uma perspectiva dual, pois o corpo é existencial, sob forma e presença no mundo. É existencial porque é por ele e a partir dele que nos relacionamos. Não é instrumento, mas se faz ser e, fazendo-se, institui-se como totalidade humana. Falar de corpo é falar de homem enquanto ser que existe em um mundo em que se relaciona. Sobre este aspecto, Morais (1999, p.78) pontua: 
Somos (e não temos) um corpo. Somos um corpo como forma e presença no mundo porque, sendo nossa presença mais apropriadamente veiculada por nosso comportamento, torna-se inverídica - ou no mínimo inacessível - no vivente a dicotomia consciência e corpo.

O entendimento de que há uma separação entre objeto e consciência cede lugar para outro. Merleau-Ponty (2006) amplia assim, a relação com a natureza e a cultura apresentando outro olhar. Propõe, desse modo, a fundação da cultura na natureza, considerados relacionais e que se influenciam mutuamente. Não haveria natureza que determinaria o homem, nem o homem que determinaria a natureza. Constitui-se, assim, um "novo" entendimento de ser. Nesse sentido, Merleau-Ponty (apud CHAUÍ, 2012, p. 160-161) afirma que

O Ser não está inteiramente vergado e achatado sobre o plano do Ser exterior. Há também o ser do sujeito ou da alma e o ser de suas idéias, e o das relações recíprocas entre as idéias, a relação inteira de verdade, e esse universo é tão grande quanto o outro, ou melhor, o envolve, visto que, por mais estrito que seja o vínculo dos fatos exteriores, não é um deles que dá razão última ao outro; juntos participam de um 'interior' que sua ligação manifesta.

A experiência é um aspecto que deve ser considerado. A compreensão da natureza e do mundo é considerada ambígua, pois oferecem imensas dimensões de sombras, já que se fizeram presentes antes mesmo da chegada do ser. A experiência, então seria anterior ao indivíduo. Merleau-Ponty (2006, p. 494) pontua que

A própria experiência das coisas transcendentes só é possível se eu trago e encontro em mim mesmo seu projeto. Quando digo que as coisas são transcendentes, isto significa que eu não as possuo, não as percorro, elas são transcendentes na medida em que ignoro aquilo que elas são e em que afirmo cegamente a sua existência nua.

Todavia, mesmo considerando que a experiência é sempre antecedida de formas mais antigas das quais não se é senhor, a experiência é aberta, permitindo diferentes incursões, retomadas e criações (MERLEAU-PONTY apud CHAUÍ, 2012). Notadamente, percebe-se nestas argumentações o aspecto relacional entre o homem e mundo.

O autor, ao discutir a relação entre fato e essência, busca encontrar a essência e a percepção interior da faticidade, ou seja, da existência e, para tanto, não toma o ser como simples consciência, mas como uma consciência perceptiva (MERLEAU-PONTY apud CHAUÍ, 2012).

Para Caminha (2012, p. 40) "A consciência não é uma coisa pensante distinta do corpo. Ela é atividade intencional encarnada em nossa existência corpórea". Nessa perspectiva, a percepção sempre se daria a partir do próprio corpo e no corpo, e enquanto corpo cognoscente, porém não desconsidera nem se pode anular uma certa dependência ao pré-reflexivo (MERLEAU-PONTY apud CHAUÍ, 2012).

Segundo Merleau-Ponty (2006, p. 494)

Se sou capaz de reconhecer a coisa, é porque o contato efetivo com ela desperta em mim uma ciência primordial de todas as coisas, e porque minha percepções são finitas e determinadas são as manifestações parciais de um poder de conhecimento que é coextensivo ao mundo e que o desdobra de um lado a outro. 
Se é através da percepção que me insiro e me relaciono com o mundo, o sensível não deve ser desconsiderado, contudo, segundo Caminha (2010, p. 73)

[...] a consciência perceptiva não tem a faculdade de constituir, de maneira antecipada, a forma do objeto sem o contato com o objeto real. Ela é incapaz de perceber sem sensações, já que é definida pela impressão de sensações. Com efeito, a experiência de perceber é essencialmente da ordem do sentir, e não, da ordem do julgar.

Quando se olha o mundo, ele é percebido de certa forma. Ao vê-se um fato ou vivenciar uma experiência, tenta-se, ao mesmo tempo, compreendê-los, porém, nesta experiência não há essências em si. O que se capta são as nossas percepções e, a medida que essas experiências são captadas, vão se construindo uma essência e uma ideia sobre o mundo. A essência não estaria na coisa percebida.

Poder-se dizer, então, que não há oposição entre fato e essência, mas o que há é um mundo operante, primeiro nome dado à instituição, e neste, a essência não é produto de nossas operações intelectuais desligadas de nossa pertença, havendo assim uma relação de articulação entre o pensamento e o mundo (MERLEAU-PONTY apud CHAUÍ, 2012).

Merleau-Ponty (apud CHAUI, 2012), apresenta o conceito de instituição para diferenciar de constituição, visto que este, a constituição, não teria sentido em mim, a não ser que por mim e para mim no instante dado. Já a instituição poderia ser definida como os acontecimentos de uma experiência, que dotam de dimensões duráveis e que possibilita um porvir.

É na experiência que o sujeito instituinte pode aparecer, contudo este não é um ser instantâneo, mas se forma em um devir. O sujeito instituinte "é aquele que põe em marcha uma atividade, um acontecimento (...) que abre um porvir. O sujeito é aquilo a quem as ordens de acontecimentos podem advir" (MERLEAU-PONTY apud CHAUÍ, 2012, p. 175)

É sob forma de sujeito instituinte que as possibilidades emergem, as portas se abrem e os caminhos passam a ser visíveis. É inserido nessa condição que se estabelece uma relação com o mundo, não a partir de determinações externas, mas a partir do externo, instituo-me como sujeito operante, cognoscente, total. Aplica-se nos casos em que o trabalho segue uma linha de desenvolvimento de assuntos contínuos, conforme a estrutura dada abaixo:

\section{REFLEXÕES FINAIS}

Refletir sobre o processo de formação humana, a partir de dois eixos principais, a sociedade e o indivíduo, constituiu-se como meta deste estudo. A luz de Pierre Bourdieu, Michel Foucault e Maurice Merleau-Ponty apresentou-se uma crítica a forma de pensar o homem ora como produto da sociedade, ora como produto de si mesmo.

Para os autores, a ênfase em um ou noutro aspecto constitui-se como um problema epistemológico da sociologia e da filosofia, visto que eleger um aspecto em detrimento a outro é desconsiderar a totalidade humana.

A sociedade como uma realidade estruturada e determinante no processo de formação do homem não consegue mais dar conta de pensar a formação do homem. Embora entendamos que estudos, como os de Émile Durkheim, tiveram contribuições para pensar a sociologia em um dado 
período, o homem constituído a partir e tão somente das estruturas sociais, de sua organização e seu funcionamento, não consegue mais explicar a ação humana, nem os motivos que levam os sujeitos a agir. Não se pode partir somente das estruturas, nem de outros lugares onde o sujeito não estaria presente.

Bourdieu, Foucault e Merleau-Ponty apresentam uma crítica a esse pensamento, todavia também não delegam o processo formativo somente a questões subjetivas. A partir de diferentes olhares, os autores pensam esse processo em uma perspectiva relacional. Não haveria assim como pensar em como me constituo desconsiderando a estrutura em que estou inserido, nem muito menos a minha subjetividade. O que sou é justamente produto da relação que estabeleço como o mundo. É nessa relação que os indivíduos vão se instituindo.

Para Bourdieu, é a partir de incorporação de padrões sociais que os agentes podem se constituir como sujeitos, produzindo novas respostas nos diferentes campos em que está inserido. O conceito de habitus apresenta-se como central no seu trabalho, visto que é produto da incorporação das disposições culturais a partir do acesso aos diferentes capitais, constituindo-se em aspecto determinante na apropriação da realidade que, embora parta de padrões incorporados, não desconsidera o elemento subjetividade.

Já Foucault parte da premissa que não se pode negar a ação objetiva da sociedade, mas esta, por mais determinante que seja, não está isenta das possibilidades de resistência. A presença do elemento subjetivo enquanto forma de inserção, enquanto sujeito, encontra espaço porque, segundo o autor, as práticas não estão isentas do poder e, por mais objetivo que seja, só pode existir na relação e, enquanto relação, as determinações escapam do controle absoluto.

Se Bourdieu e Foucault principiam sua crítica na ênfase na estrutura, Merleau-Ponty faz o caminho inverso, analisando a excessiva proeminência nos aspectos subjetivos. Sem uma infraestrutura não é possível instituir-se, pois ela é que fornece o "instrumental" para ação. $O$ autor ainda acrescenta, sem desconsiderar a infraestrutura, que é a partir da percepção, por conseguinte, de uma consciência perceptiva, que o sujeito se relaciona como o mundo, consciência essa que só é possível a partir da experiência e enquanto sujeito instituído e, por isso mesmo, como sujeito de si.

É, portanto, na experiência que adquirimos a condição de sujeito, um condição que se aproxima da que expressou Freire (apud OLIVEIRA et al., 2015, p. 10) "[...] sei que a minha passagem pelo mundo não é predeterminada, preestabelecida [...] gosto de ser gente porque a História em que me faço com os outros e de cuja feitura tomo parte é um tempo de possibilidades e não de determinismo".

Para finalizar, ratificamos que no nosso entendimento, o conhecimento é provisório e por isso mesmo, não pode se constituir como verdade absoluta, de qualquer forma, o aspecto relacional sociedade/subjetividade na formação do homem apresentados por Bourdieu, Foucault e Merleau-Ponty inserem-se na atual conjuntura como reflexões mais aproximadas para explicação dessa formação e, mesmo que apresentem limitações, materializam-se como efetivos e importantes para pensar o homem, seja a partir das teorizações dos autores, seja a partir do diálogo com outros saberes. Essa importância não se pode negar. 


\section{REFERÊNCIAS BIBLIOGRÁFICAS}

1. ALMEIDA, Rogério José de. $\mathbf{O}$ indivíduo e a sociedade no pensamento de Durkheim. Texto inicialmente apresentado para a disciplina Teoria Sociológica I do Programa de Mestrado em Sociologia da Universidade Federal de Goiás - UFG, 2011. Disponível em http://professor.ucg.br/SiteDocente/admin/arquivosUpload/14764/material/Artigo\%20\%20Durkheim\%20-\%20Indiv\%C3\%ADduo\%20e\%20Sociedade.pdf. Acesso em 10 de abril de 2013.

2. BAUMAN, Z. O mal-estar na pós modernidade. Rio de Janeiro: Jorge Zahar, 1998.

3. BERGER, P. e LUCKMANN, T. A construção social da realidade: tratado de sociologia do conhecimento. 12. ed. Petrópolis: Vozes, 1995.

4. BOURDIEU, P. Razões práticas: sobre a teoria da ação. 10. ed. São Paulo: Papirus, 2010.

5. CAMINHA, Iraquitan de Oliveira. Corpo, subjetividade e motricidade em Merleau-Ponty. In: CAMINHA, Iraquitan de Oliveira. Merleau-Ponty em João Pessoa. João Pessoa: Editora Universitária UFPB, 2012.

6. CAMINHA, Iraquitan de Oliveira. O distante-próximo e o próximo-distante: corpo e percepção na filosofia de Merleau-Ponty. João Pessoa: Editora Universitária UFPB, 2010.

7. CATANI, Denise B. A educação como ela é. In: Bourdieu Pensa a Educação. Biblioteca do professor. Revista Educação: Bourdieu Pensa a Educação. São Paulo, 2a Ed. v. 2, n.5, p. 16-25, 2012. ISSN 1415_5486.

8. CHAUÍ, Marilena. Merleau-Ponty: da constituição à instituição. Dois pontos. Curitiba, São Carlos, v. 9, n. 1, p. 155-180, abr de 2012.

9. DUBAR, Claude. A crise de identidades: a interpretação de uma mutação. Tradução: Catarina Matos. Porto: Edições Afrontamento, 2006.

10. DURKHEIM, Émile. Sociedade como fonte de pensamento lógico. In: RODRIGUES, José Albertino (org.). Durkheim. Tradução: Laura Natal Rodrigues. 6. ed. São Paulo: Ática, 1993.

11. FOUCAULT, M. O sujeito e o poder. In: DREYFUS, Hubert. L. Michel Foucault, uma trajetória filosófica: (para além do estruturalismo e da hermenêutica). Tradução: Vera Porto Carrero. Rio de Janeiro: Forense Universitária, 1995.

12. GOMES, Ivan Marcelo, ALMEIDA, Felipe Quintão de \& VAZ, Alexandre Fernandez. Sobre corpo, reflexividade e poder: um diálogo entre Anthony Giddens e Michel Foucault. In: Política \& Sociedade, v. 08, n. 15, p. 299-319, out. 2009.

13. GONÇALVES, Nádia G. e GONÇALVES, Sandro A. Pierre Bourdieu: educação para além da reprodução. Petrópolis: Vozes, 2010.

14. MEKSENAS, Paulo. Sociologia da educação: introdução ao estudo da escola no processo de transformação social. 8. ed. São Paulo: Loyola, 1998.

15. MERLEAU-PONTY, Maurice. Fenomenologia da Percepção. Tradução: Carlos Alberto Ribeiro de Moura. 3. ed. São Paulo: Martins Fontes, 2006.

16. MORAIS, J. F. Régis de. Consciência corporal e dimensionamento do futuro. In: WEY, Moreira Wagner (org.). Educação Física \& esportes: perspectivas para o século XXI. 4. ed. Campinas: 
Papirus, 1999.

17. MORIN, Edgar. Os sete saberes necessários a educação do futuro. Tradução: Catarina Eleonora F. da Silva e Jeanne Sawaya. 12. ed. São Paulo: Cortez; Brasília: UNESCO, 2007.

18. NIETZSCHE, Friedrich W. Sobre verdade e mentira no sentido extra-moral. São Paulo: Hedra, 2007.

19. OLIVEIRA, Francisco Vieira de, CORREIA, Nayara Kelly, CÂMARA, Helder Cavalcante \& DUARTE, Suênia de Lima. $O$ agir reflexivo na escola: uma condição necessária para o exercício docente? In: Redfoco, v. 2, n.1, p. 03-12, 2015.

20. ROSO, C. C. O cuidado de si de pessoas com insuficiência renal crônica em tratamento conservador. Dissertação apresentada ao Curso de Mestrado do Programa de Pós-Graduação em Enfermagem, Área de concentração Cuidado Educação e Trabalho em Enfermagem e Saúde, Linha de Pesquisa Cuidado, Educação em Enfermagem e Saúde, da Universidade Federal de Santa Maria (UFSM, RS), 2009.

21. SILVA, Tomás Tadeu da. Documentos de identidade: uma introdução as teorias do currículo. 2. ed. Belo Horizonte: Autêntica, 2007. 